\title{
Transitar la vía del desarrollo: entre ausencias y envidias
}

Traveling the development way: between absences and envies

\section{REsUMen}

A través de una conversación re-creada sobre y con las mujeres de la Asociación de Mujeres Emprendedoras de Guatavita (AMEG), este artículo pretende mostrar de qué manera en AMEG se encuentran caminos para transitar la vía del desarrollo. Esto implica enfrentarse, aceptar, adaptarse, ocultarse y subvertir los supuestos tecnocientíficos y la normatividad internacional del sector lácteo en Colombia. Este tránsito se da entre formas productivas sinérgicas, en las que se conjuga la reciprocidad, los saberes-haceres propios, el cambio y la envidia. Esta última, se convierte en una manera de regular la acumulación para mantener la reciprocidad y, a la vez, es una explicación de los fracasos de los proyectos que llegan a la asociación.

Palabras clave: desarrollo rural, tecnociencia, envidia, mujer campesina.

\section{Abstract}

Through a re-created conversation about and with the women of the Asociación de Mujeres Emprendedoras de Guatavita (AMEG) the purpose of this article is to show how the women of AMEG find ways of traveling the development way. This implies facing, accepting, adapting, hiding
María Alejandra

Alfonso Sarmiento

Antropóloga Pontificia

Universidad Javeriana.

Bogotá, Colombia.

$\square \mathrm{m} \_a l f o n s o @ j a v e r i a n a . e d u . c o$

(1) ORCID: 0000-0002-9045-7252

$\Delta$ Google Scholar 
and subverting the technoscientific assumptions and the international regulations of the dairy sector in Colombia. This traveling occurs between synergistic productive forms in which reciprocity, know how, change and envy are combined. Envy becomes a way of regulating accumulation to maintain reciprocity and, at the same time, is an explanation for the failures of the projects that reach the association.

Keywords: rural development, technoscience, envy, peasant woman.

\section{Introducción}

ste artículo es resultado de mi trabajo de grado, así que este
camino comenzó mucho antes. Cuando me sugirieron hacer de
mi investigación un artículo pensé que, tal vez, el mayor reto sería sintetizar el trabajo de grado en las casi treinta páginas que aquí presento, el reto estuvo en reorganizar las ideas para hacerlas comprensibles. Me encontré escribiendo bajo la suposición de que usted, lectora, conocía lo que yo sabía, o pegando y copiando cosas que para mí eran esenciales e inmutables en el escrito, pero que al leerlo parecía que ya no tenían un lugar. En cierto sentido los caminos de La Carbonera Baja, donde hice mi trabajo de campo, eran así; cuando pedí indicaciones, las personas suponían que yo tenía conocimientos básicos, como saber que era un encintado ${ }^{1}$. Así mismo, un camino recto que parece inamovible resulta ser una ilusión que casi nadie transita, pues la mayoría prefiere acortar camino por las verjas.

Así que escribí estos párrafos para poder comenzar un camino nuevo a partir de los recorridos que ya he hecho, para tratar de desnaturalizar los conocimientos que he hecho obvios y para mutar esos párrafos que me parecen inamovibles. Al final que es este comienzo, me di cuenta que para mí paz mental intenté crear este artículo como una vía pavimentada y lineal, siguiendo esa paz de la ciencia que me obliga a organizar de una manera tan reducida. Para mi paz espiritual (si se puede llamar así) no logré organizarlo de esta manera, así que es más probable que usted, lectora, recorra este camino de letras entre baches, giros y entradas sin salida, pero no se desanime, le prometo que es en el camino, y no en las conclusiones, donde se encuentra el verdadero sentido de este texto. Para comenzar vale la pena hacer algunas aclaraciones, así que vamos a lo siguiente. 


\section{Introducir esta conversación}

Esta conversación comenzó en la Asociación de Mujeres Emprendedoras de Guatavita (AMEG), junto a quienes realicé la investigación. Esta asociación se encarga del acopio de leche y la producción de algunos derivados lácteos como yogures, quesos y panelitas de leche. Se encuentra en la vereda La Carbonera Alta, ubicada en el municipio de Guatavita, Cundinamarca. La vereda tiene una extensión de $14.60 \mathrm{Km} 2$ y se encuentra a $10.3 \mathrm{Km}$ de distancia del casco urbano del municipio (Alcaldía Municipal de Guatavita, 2014). La mayor parte del municipio presenta relieve montañoso con alturas hasta los 3.800 m s.n.m., por lo que tiene un clima frío con zonas de páramo y subpáramo dentro de su territorio (Villarraga, 2013).

La asociación está conformada por 24 socias y más de treinta proveedores, la mayoría de ellas y ellos son adultos mayores que producen poca leche y la entregan a AMEG de manera intermitente. Por este motivo, la asociación debe tener una larga lista de proveedores que les permita abastecer la producción de la asociación y vender algo de leche a la empresa El Pomar. Patricia Rodríguez y Gilma Rodríguez son las líderes de la asociación, esto significa que tienen funciones específicas como ir a las reuniones con las entidades de control (Cámara de Comercio, INVIMA, gobernación, etc.) y son las que manejan toda la documentación de AMEG. Junto a ellas están Leonor Rodríguez e Hilda Jiménez quienes se encargan de realizar la producción. A su lado trabajan Orlando Sarmiento y Daniel Cortez quienes se ocupan del acopio de leche; a diferencia de las otras trabajadoras ellos no están asociados.

Al conocer la asociación quería entender cómo entraban algunas tecnologías a esta vereda, pero con el tiempo este interés fue cambiando. En la asociación se estaba realizando el proyecto de "Mejoramiento de la productividad y la competitividad del sector lácteo en Cundinamarca" financiado por la Cámara de Comercio y el Programa de Transformación Productiva (PTP). Me di cuenta que ser parte de estos proyectos era muy usual en la vereda y era una constante en la asociación. Por eso, mi interés se movió hacia las formas en las que las asociadas se relacionan con estos proyectos, lo que finalmente se tradujo en las preguntas que guían este artículo, ¿por qué llegan los proyectos de desarrollo al lugar?, ¿qué discursos tienen detrás?, ¿qué implica la asociación y ser asociada?, ¿cómo se relacionan las formas productivas locales con los nuevos proyectos?, ¿qué hace posible mantener las formas de vida y producción de estas mujeres? 
Indagar sobre los discursos que están detrás de este tipo de proyectos de desarrollo rural me llevó a cuestionar mi propio papel como científica (social); de esta manera entiendo que la escritura es una tecnología, que la ciencia moderna puede llegar a instaurar como desapasionada, sobria e impersonal y que puede invisibilizar a aquellas personas que me dieron el conocimiento, a desacreditar sus formas de hablar, pensar y sentir (Vargas-Monroy, 2010). Por eso, este es un intento de darle sentimiento a las teorías a través de las palabras de las mujeres con las que conversé, que remiten a la experiencia cognitiva y emocional que yo experimenté mientras las mujeres me enseñaban sus múltiples caminos. Siguiendo la intención de Molano (1998), quiero resaltar el conocimiento que yace en la emoción del lenguaje popular y que supone un alejamiento a la sequedad del lenguaje académico, así como las posibilidades de difuminar lo particular y lo genérico en una narración.

Por eso, en este artículo la invito a usted, lectora, a unirse a mi conversación, pero, para lograr entablar esta comunicación, es necesario hacer una re-creación, esto es, armar relatos que hasta cierto punto son ficticios, pero que "están construidos a partir de conversaciones y relaciones existentes con las personas en campo" (Gallego, 2018, p. 17). Así, escribo mezclando dos estilos: el primero busca "re-crear" una conversación explicativa con las formas y las palabras de las mujeres con las que trabajé ${ }^{2}$, esto me permite ver el texto como parte de muchas otras conversaciones que se dieron en campo, siendo "el campo mismo es una perpetua discusión" (Gudeman y Rivera, 1990, p. 4). La segunda voz que uso es la de académica, que escapa por ser la mía; a través de ella buscó vincular explícitamente los conceptos para hacerlos evidentes.

Esos vaivenes muchas veces abruptos entre una forma de escribir y otra, es de cierta forma la mediación que deben hacer las mujeres de la vereda al relacionarse con los proyectos de desarrollo que llegan al territorio; escribir con dos voces fue, de alguna manera, una forma de representar ese movimiento que hacen las personas. De modo que fueron sus palabras las que me ayudaron a hacer esa mediación entre las teorías y la experiencia, así, "frente a los conceptos de la academia, creo que el lenguaje de la gente, el lenguaje directo es el gran instrumento de análisis" (Molano, 1998, p. 104).

Esto permite también hacer evidente que hay una conversación, es decir, que cuando le hablo a USTED evidencio la presencia de una lectora y también de una narradora, por ejemplo, cuando digo "usted lectora 
conocía lo que yo sabía" se entiende que yo le estoy hablando a alguien, a usted (por eso tampoco es casual que, muchas veces, le hable a usted en femenino). En cambio, cuando digo, "Europa coloca algunas barreras no arancelarias como las normas sanitarias", no remite a una conversación y sus hablantes, sino a hechos/verdades, el yo implícito de la conversación desaparece, así como usted, lectora. De esta manera, en el contraste de las voces se puede observar lo difícil que resulta verme a mí misma, sobre todo cuando soy una narradora académica, pues comienzo a hablarle a alguien no nombrado. El no nombrado hace referencia a un sujeto blanco, hombre y heterosexual, que por tener estos rasgos privilegiados detenta el poder de decir verdades objetivas. Su poder recae en que no se ve, aparece como un simple vocero de los hechos (Haraway, 2004). Cuando escribo, ¿a quién imaginó que le escribo?, ¿quién imaginan que soy las personas que me leen?

\section{El problema: por un campo productivo, competitivo y moderno}

Desde los años setenta se ha visto la productividad como un factor decisivo en el desarrollo rural de Colombia (Kalmanovitz y López, 2003). A esta idea se sumó la competitividad al instaurarse las políticas de apertura neoliberal que se venían planteando desde los años ochenta en el país, pero que se consolidan a partir de la década de los 90 (Pérez y Farah, 2002). La combinación de estos ideales trae la transferencia tecnológica como base de la supuesta reforma del campo. En consecuencia, se genera un sistema productivo que demanda grandes sumas de capital para la producción, lo que a su vez

(...) redujo en más de una quinta parte la superficie sembrada, en especial de cultivos temporales propios de la agricultura campesina (...) Entre 1990 y 2005 el área sembrada con cultivos transitorios pasó del 51,1\% al 41,5\% de la superficie en producción y de 2.366 a 1.687 millones de toneladas. (Fajardo, 2018, pp. 161-228)

Por eso es mejor para usted como campesina tener un chilito chiquito de papa y el resto para las vacas o solo sacar leche. Porque las vaquitas siempre dan, en cambio la papa es como Dios y suerte será. Esta inestabilidad de los cultivos como la papa, ocasiona lo que autores como Suárez (2011) llaman una "ganaderización" de Colombia.

Posteriormente, la política neoliberal se intensifica por la firma del TLC con Estados Unidos, que se venía trabajando desde el 2006, pero que se concreta en el 2010. Esta intensificación afecta nuevamente a los campesinos del país, pues Colombia entra al tratado con una evidente 
desventaja, ya que Estados Unidos es uno de los mayores productores a nivel mundial de bienes alimenticios como carnes de aves y res, maíz, sorgo, soya, leche, huevos, miel y algodón. Además, Estados Unidos mantiene las protecciones, los subsidios a sus productos y exige medidas sanitarias unilaterales para los bienes colombianos (Fajardo, 2018). Paralelo a los tratados con Estados Unidos, se da la firma del Tratado de Libre Comercio (TLC) con la Unión Europea, en la cual se pretende extender las posibilidades comerciales de ambos países. Sin embargo, Europa coloca algunas barreras no arancelarias como las normas sanitarias y los bajos precios de sus productos, que son subsidiados por los gobiernos. De esta manera, Europa busca liberar la sobreproducción continua de leche expandiendo sus productos a países como Colombia (Suárez, 2011).

La respuesta del gobierno colombiano ante este panorama fue exigir una suma de dinero a Europa para invertir en el mejoramiento de las condiciones sanitarias de la producción láctea, para que pudiera ingresar a los mercados extranjeros (Suárez, 2011). Esto se tradujo en la implementación de varios proyectos de desarrollo enfocados en la competitividad del sector (Conpes 3675 del 2010) y en el fortalecimiento de instituciones de control sanitario (Conpes 3676 del 2010), enfocadas en reducir la cadena informal de leche, que representaba el 50\% de la producción del país.

Así, bajo los Conpes del sector lácteo, se comienzan a crear proyectos de desarrollo como el de "Mejoramiento de la productividad y la competitividad del sector lácteo en Cundinamarca" al que se suscribió la asociación. Estas normas y, por ende, este proyecto derivado, parten de tres supuestos: la competitividad, la productividad y la higiene (sanitarios), que a su vez tienen tres dimensiones: primero son saberes científicos, es decir que son creadas por un conocimiento que se considera a sí mismo racional, verdadero, objetivo, medible, que nada tiene que ver con las campesinas y las consecuencias que genera en la realidad, pues la ciencia funciona igual sin importar dónde se haga (Haraway, 2004 y Giddens, 1997). Esas verdades irrefutables son expresadas a través de científicos expertos a los que Haraway (2004) llama un nuevo tipo de testigo modesto. Estas personas solo pueden ser racionales, sin sentimientos y totalmente objetivos, como los y las capacitadoras que van a la asociación, con esas diapositivas que tienen fotos de vacas enormes con ubres rosadas y gordas o fotos de bacterias que usted nunca ha visto, para enseñarle sin preguntarle lo que usted sabe. Como este científico es racional, sigue pasos estrictos y no se vincula a nadie, pues no puede tener la culpa de lo que hace o de las consecuencias que traen sus acciones, él solo conoce y cuenta la verdad. 
Las otras dos dimensiones de esos conceptos son la técnica y la tecnología, que remiten a los momentos en los cuales las ideas de ese científico se practican. Así, la técnica es la mediación que se debe hacer para llegar a un fin o meta, en la que se articulan humanos y no humanos (Latour, 2001). Con la tecnología me refiero a elementos materiales como insumos, maquinas, ciertos pastos y ciertas vacas, que generalmente son los beneficios de los proyectos. Se supone que estos dos lados nacen de las ideas científicas y por ende deben funcionar en todo lugar de la misma manera. Pero en la realidad no se trabaja con vacas irreales o con bacterias invisibles, generalmente las cosas no suelen salir como en el laboratorio, así que los capacitadores culpan a las personas por no entender la ciencia y por eso dañar la técnica y la tecnología. Si alguno de los conceptos llega a funcionar se le agradece a la ciencia y sus avances, no a las personas que conocen el entorno y que han aplicado todos los procesos. Por eso, tomamos el concepto de tecnociencia que pone de relieve las implicaciones de la hibridación de la ciencia, la técnica y la tecnología (Echeverría, 2001; Haraway, 2004).

Esta mezcla se convierte en un problema para usted como campesina $y$ asociada porque son unas peticiones muy estrictas, eso toca cumplir con requisitos sanitarios, más insumos y certificaciones. Además, entra uno a competir con empresas grandes como Alpina y eso piden los mismos requisitos para uno y para esos. Entonces es ahi en la parte comercial donde se falla, porque el mercado está lleno de productos con marca y precios bajos. Esta preocupación de las asociadas muestra cómo las condiciones empresariales (capital de inversión, infraestructura, cadenas especializadas, etc.) se convierten en el patrón de medida y el ejemplo de valores necesarios para ser competitivos (Salgado, 2002). Esto a su vez, se enmarca en una razón proléptica (De Sousa Santos, 2006), según la cual debemos encaminarnos hacia el progreso y el crecimiento económico, pues estamos en un tiempo lineal. Para que estos dos preceptos funcionen, debe haber lo que De Sousa Santos (2006) llama una monocultura del saber y el rigor, y una monocultura del productivismo capitalista. En la primera, se invalidan los conocimientos campesinos y las personas que los usan, considerándolos y creándolos como ignorantes (ausentes). Mientras que la segunda, solo ve el crecimiento económico dentro de unos ciclos controlados y artificiales, que desconocen otras formas de productividad que pueden estar atravesadas por ciclos ecológicos.

Además, como se niega la hibridación entre ciencia, técnica y tecnología, se oculta el proceso de construcción de conocimiento científico que debe pasar por el error y se silencian los conocimientos de las personas no expertas, que apropian las tecnologías y muchas veces las 
hacen funcionales. Así, la pretensión de neutralidad y veracidad hicieron que la ciencia y la tecnología se convirtieran en la forma de expansión del desarrollo; convirtiéndolo en un bien para ser vendido o transferido a los nuevos usuarios creados para el desarrollo, es decir, los subdesarrollados, ausentes e ignorantes (Echeverría, 2001; Hobart, 2002). De esta manera, el desarrollo se legitima equiparando procesos productivos alternos con pobreza e ignorancia (Shiva, 1996).

La limitación de este tipo de ciencia para ver otras formas de producir hace cada vez más difícil mantener a las asociadas, pues con la entrada de nuevas tecnologías cuentan con pocas vacantes para trabajar, lo que no ha significado disminuir los costos de producción. Todo esto ha mermado la capacidad económica de la asociación, lo que se traduce en una incapacidad total para devolver algún beneficio a las mujeres por estar asociadas. Así, la asociación se encuentra atrapada entre discursos contradictorios y sofocantes, que terminan por hacer imposible su continuidad. De esta manera, se va dejando el mercado a unas pocas grandes empresas que tienen la capacidad de cumplir los requisitos, financiar publicidad y transportar los productos. Así mismo, son empresas que tienen el poder de excluir personas, como a los adultos mayores que producen poca leche y de "baja calidad" (por ejemplo, Alquería compra un mínimo de 80 litros por finca, un asociado de AMEG adulto mayor puede vender de 5 a 12 litros).

Esto la va a afectar a usted como mujer productora de manera especial, porque ya no tiene a quien venderle la leche y tampoco a quien venderle el queso, como se hacía antes de la asociación; como ahora todo toca certificado... Los hombres todavía pueden trabajar en el jornal o tener su asocio de papa, pero usted se vuelve invisible, como ausente de este mundo, porque ya a esa edad no contratan a nadie en los restaurantes o en las flores y sin poder mantener las vacas, sin trabajar, ¿qué se es? Autoras como Shiva (1996) han profundizado en la marginación progresiva que han sufrido las mujeres en la elaboración de derivados lácteos y advierten que, con los oligopolios, corren el riesgo de quedar excluidas de la producción de leche y de la protección de las vacas.

Así, en la tecnociencia se configuran "sujetos y objetos, subjetividad y objetividad (...), bajo formas que debilitan otras maneras de hablar sobre ciencia y tecnología" (Haraway, 2004, p. 68). Por eso, se crean directrices como "las buenas prácticas de manufactura" y "las buenas prácticas ganaderas", éstas se refieren a los modos de actuar recomendados por la normatividad para la producción de alimentos, e incluyen requisitos en cuanto al tratamiento de medicamentos, la alimentación de los animales, 
la higiene en el ordeño, el saneamiento de instalaciones, etc. Mediante estas prácticas se pretende "proteger la vida, la salud y la seguridad humana y prevenir las prácticas que puedan inducir a error, confusión o engaño a los consumidores" (ICA, 2007). Implícitamente se crean a la vez las "malas prácticas" que son aquellas actividades reprimidas o invisibilizadas por los expertos que llegan al lugar; éstas por lo general se refieren a los saberes-haceres campesinos.

Así, las instituciones como el INVIMA y la normatividad para el sector lácteo pretenden no sólo controlar la producción sino también los cuerpos y subjetividades de las campesinas. Porque no es que uno como campesina haga las cosas cochinamente, sino que piden registro de todo, contratar las empresas que el INVIMA diga para revisar la maquinaria, que son más costosas, usar muchos insumos y una infraestructura grandísima. Pero toca hacerlo, porque donde uno no cumpla todos los requerimientos le cierran la asociación y lo multan.

\section{Caminar junto a las asociadas}

Pero las vías del desarrollo son más intrincadas de lo que suponen sus directrices, así que debemos hablar de los movimientos que han creado las asociadas y las directivas para usar el desarrollo según sus propios objetivos comunitarios o personales. Ese cambio de objetivos y metas a favor de las mujeres campesinas es conflictivo, pues los capacitadores suelen reprimir las acciones contrarias a lo planteado en el plan. De esta manera, más que escuchar los problemas y encontrar la raíz de los conflictos, los veedores y capacitadores intentan callar a las asociadas con la salvaguardia de que los líderes de la asociación pactaron previamente lo que se iba a realizar. Claro, usted como proveedora no va a dejar que se le metan a la casa y eso es lo que intentan hacer todas esas leyes, esas normas, esas "buenas prácticas" que traen los proyectos, esos que buscan enseñarle cómo cargar la vaca, como mantener el ternero, hasta cómo debe ordeñar; sin saber que las mujeres antes de soltar la teta de la madre ya estaban sacando la leche de la teta de la vaca. De esta manera, la modernización pretende influir en los rasgos más íntimos de la vida personal, que comienzan a relacionarse con extensiones espacio temporales indefinidas (Giddens, 1997), como la normatividad láctea internacional.

Pero no solo se le meten a la casa, también pretenden que no trate a la propia familia. Por ejemplo, si usted deja de prestar el toro para montar las vacas del pariente o del vecino, como sugieren los capacitadores, eso sin dudas le dejaría la fama de ser una mujer creída y no faltarían los envidiosos que comienzan a armar chisme y a robarle la monta del toro. Por eso, sin 
importar lo que digan los capacitadores y veedores, a usted le toca seguir prestando el toro o pidiéndolo al vecino. Porque además así se carga rápido la vaca y no toca comprar más insumos, como pasa con las pajillas que traen los técnicos. Si usted fue a todas las capacitaciones en la asociación, debe saber que en el proyecto se estaban dando unas pajillas para inseminación artificial de toros de Estados Unidos, con el fin de mejorar la genética de los animales de las asociadas. En las mismas capacitaciones muestran que hay un rango de falla de dos de tres pajillas, es decir que a usted como proveedor le toca comprar mínimo tres pajillas para cargar una vaca y cada una tiene un costo mínimo de 20 mil pesos, dependiendo la raza del toro, o sea que eso sale carísimo.

El préstamo de toro es una práctica que busca reproducir las vacas para continuar la producción sin una inversión extra, esto hace parte de distintas estrategias que existen en el saber campesino de esta vereda para mantener las fincas produciendo. Había dos conceptos que usaban las personas en la vereda que condensan el sentido de estas estrategias, que en muchos casos chocan con la normatividad: ellos y ellas hablaban de "rendir" y de "escurrir". Esto significa aprovechar al máximo las potencialidades de los objetos, los tiempos, los procesos y las actividades. Por eso, usted tiene que "escurrir" la vaca, es decir, sacar toda la leche del animal, para que no le dé mastitis y no se desaproveche ni una gota de la leche que está en la ubre. Por otro lado, hay veces donde las cosas "rinden", que es cuando alcanzan para todo el mundo, más de lo que se había esperado. Por ejemplo, un mercado que alcanza para mandarle a los hijos que viven en la ciudad o una chucula ${ }^{3}$ al que se le echa un poco más de agua y alcanza para la visita inesperada. El tiempo también puede "rendir" cuando una actividad se demora menos de lo que pensaba, por ejemplo, hay mujeres que les "rinde" el ordeño a mano más que con máquina (se demoran menos).

A eso Max-Neef y Elizalde (1993) lo llamarían usar satisfactores sinérgicos, que son formas de suplir varias necesidades por medio de un mismo proceso, acción u objeto. Eso incluye las relaciones de vecindad y parentesco, que significan mano de obra, remesas o diversificación de las ocupaciones, que permiten hacer frente a las situaciones desfavorables del mercado o el clima (Van Der Ploeg, 2000; Mora, 2008). En este sentido, las personas eligen satisfactores sinérgicos, que no requieren una adopción de una tecnología "nueva", sino el refuerzo de algún saber "viejo". Por ejemplo, en vez de comprar pajillas de inseminación, se pide prestado el toro, que no requiere inversión en dinero, las vacas cargan mucho más 
rápido y se afianzan los lazos de reciprocidad. Siguiendo a Mauss (1971) esto último es fundamental, pues remite a un entramado circular de relaciones de dar, recibir y devolver, que estabiliza los lazos familiares, vecinales e incluso, entre cooperativas (la competencia).

Siguiendo con las funciones sinérgicas del préstamo del toro, esta práctica permite conocer las cualidades de la cría (pues se conoce al toro) y tener razas adaptadas al clima y las condiciones del suelo en el que viven. Por esto mismo, las personas prefieren dejar las crías de sus propias vacas y evitan la compra de vacas nuevas genéticamente seleccionadas. Pues estos animales de gran tamaño suelen tener más problemas de salud (como propensión a la mastitis y patas débiles) y les da mal de altura, por las bajas temperaturas del lugar. Este conocimiento ha sido trabajado por autores como Shiva (1996), quien sostiene que la hibridación del ganado cuando es guiada por las ideas reduccionistas de la ciencia, crea crecimiento ficticio y en realidad termina por generar más riesgo a las campesinas.

Por eso es mejor que usted tenga muchas vacas que den poca leche, porque si llega a morir una o dos vacas de las grandes ¿cómo recuperar los millones que valió esa vaca? eso es mucho riesgo. Además, a usted le alcanzaría para tener unas tres vacas de esas grandes, donde se le muera una sola vaca, pues se quedó sin un tercio de la producción. Pero si usted compra de las pequeñas, le alcanza para unas seis vacas, si se le muere un animal pierde pocos litros y sigue con las otras cinco vacas. Por eso, cuando en una capacitación preguntan a las asociadas si les gustaría tener una vaca de 35 litros, las mujeres casi como un coro dicen que no. Doña Lilia Rodríguez explica que "esas son vacas desechables", pues no duran más de dos o tres partos (Capacitación inseminación artificial, Diario de campo, 24 de julio del 2018). Así mismo lo explica Van der Ploeg (2010), quien sostiene que el tipo de producción láctea empresarial degrada a los animales convirtiéndolos en productos desechables, esto termina por disminuir los beneficios de la leche que estos producen.

Las mujeres reconocen estas problemáticas de una forma de producción capitalista, pero a la vez saben que pueden aprovechar los insumos que llevan estos proyectos de desarrollo. Por eso, el chisme y la crítica entre las beneficiarias se convierten en una parte importante para transitar los caminos trazados por el proyecto. Pues cuando usted esparce un chisme está criticando las propuestas, al punto de llamar la atención de los veedores y capacitadores sobre injusticias y fallas. Así, las mujeres dejan de ser un ente ignorante (pasivo-receptor) y comienzan a involucrarse activamente en los procesos del proyecto, pues cuestionan los supuestos básicos de los capacitadores y de los mismos planes; es lo que Scott (2000) 
llamaría una forma cotidiana de resistencia. Esta astucia e improvisación que pueden desplegarse para doblegar la burocracia a los propios intereses (Micarelli, 2014, p. 109), no se limita solamente a hablar acerca de los beneficios y sus falencias. Usted debe pensar maneras de usar las cosas que le dan, para lo que se necesita en la casa o en la finca.

Por eso, no se deben criticar los objetos que se dan, sino que se buscan las maneras de aprovecharlos, no se rechazan las capacitaciones, sino que se busca quién puede usarlas. Le puede decir a una vecina que vaya un día que usted no pueda, ella solo tiene que firmar la asistencia como si fuera usted. A veces los capacitadores se dan cuenta, pero eso dejan así, pues en el fondo saben que esas cosas son las que mantienen en pie el proyecto y las capacitaciones, porque con tanto que hacer a muchas no les queda lugar. Otra cosa que usted puede hacer es, si le dan algún insumo que no le sirve o que no necesite, encuentra la forma de venderlo, usted espera a que los del proyecto se vayan, esos después no vuelven. La plata de los objetos le sirve para pagar deudas, comprar animales $u$ otros insumos que necesite para mantener las vaquitas. Moverse de esa forma hace parte de los conocimientos campesinos: es "escurrir" al máximo las posibilidades, pues acá no se desperdician ni las capacitaciones.

Por otro lado, Siguiendo a Scott (1998) podemos ver que hay ciertas reglas formales como las de productividad, estas suponen uso de pajillas, establos, insumos y capacitaciones técnicas, pero en la realidad estas son parasitarias de los procesos informales como el préstamo del toro, ordeño en potreros con la familia, venta de beneficios y suplantación en la asistencia a las capacitaciones. El esquema formal no reconoce estas acciones, pero sin ellas no podría existir y, por sí solo, no las puede crear o mantener. Esta dependencia de los esquemas formales a los informales está oculta por la relación asimétrica en la que están envueltas las campesinas y que ya hemos visto en referencia a la tecnociencia. Según Wolf y Cirlot (1971), los campesinos se encuentran subordinados a los dirigentes de una sociedad más grande a la que pertenecen; así mismo, autores como Salgado (2002) reconocen que las políticas del sector rural en Colombia le siguen otorgando un papel subordinado a los campesinos. Esto, ya que imaginan a estas personas a partir de intereses concretos (internacionales) y no reconocen las múltiples transformaciones que han transitado.

\section{Moverse por las vías del desarrollo: ni "envidiadas" ni "enlechadas"}

Gilma y Patricia Rodríguez (las directivas) han construido caminos distintos, pues deben moverse entre el saber y la humildad, entre las palabras técnicas y las cotidianas, entre el cambio y la permanencia y, 
finalmente, entre la casa y la asociación. Las directivas de la asociación se convierten en mediadoras entre el mundo de reglas tecnocráticas y las realidades locales. Deben caminar por lo que Chatterjee, Cháves y Hoyos (2011) llamarían la sociedad política, en la que las asociaciones negocian con las entidades estatales usando los límites de lo prohibido y las expectativas que tiene el gobierno de administrar las poblaciones "más desfavorecidas". Así, las directivas se convierten en traductoras, lo que les otorga el derecho de representar a un grupo silencioso, pero al mismo tiempo deben realizar un desplazamiento constante de los intereses y mecanismos de unos y otros (Callon, 1995). De esta manera, deben conciliar las propuestas de los proyectos (que dada su poca flexibilidad se convierten en órdenes) con los intereses de los beneficiarios. Ese desplazamiento no es sencillo, ya que, a pesar de ser una asociación los intereses individuales pueden variar y las propuestas de los proyectos pueden ser poco viables. El trabajo del líder no sólo consiste en informar, sino en convencer de los beneficios, en persuadir a las personas de ceder en sus decisiones y exigir a los proyectos cumplir con las promesas hechas.

Ejercer este rol mediador tiene sus riesgos, pues las directivas deben afrontar las críticas constantes de las asociadas, de familiares y de vecinos, pues hacen parte de aquellos que "tienen más"; así la crítica se convierte en una forma de regular las desigualdades presentes en la vereda. Esto ya que, demostrar que se tiene poco, que se tienen problemas o necesidades, es deseable frente a los vecinos y familiares; para no levantar envidias es mejor tener solo lo necesario. Por eso, se escuchan justificaciones sobre las posesiones de cada persona, como "yo tengo esas vacas, pero eso dan un goto de leche", "yo tengo, pero es con la vecina" y "como las vacas lo mantienen a uno, uno tiene que mantenerlas, todo eso es plata". Las necesidades no la hacen a usted menos que otra persona, nadie la va a juzgar por tener necesidades, ni la van a presionar para que deje de tenerlas, pues si no se tienen necesidades, ¿para que se trabaja?, es parte de la vida. Por eso, usted no puede "enlecharse", es decir acumular leche, producir más de la necesaria o de la que puede guardar. En la vereda eso pasa poco y si sucede es por poquito tiempo, cuando no se han sacado las vacas próximas al parto. Pero es una preocupación a nivel nacional, pues las empresas se están "enlechando" y van a dejar de pagar "bueno" por la leche.

Así, las necesidades son carencia y potencia pues, al vivir solo con lo necesario, hay una motivación continua para seguir trabajando y mantener un equilibrio (Max-Neef y Elizalde, 1993, p. 34). Al trabajar y producir solo lo necesario, también se vuelve obligatorio reproducir las estrategias económicas que hemos mencionado, pues éstas permiten tener esas inversiones, ahorros y producciones de bajo costo. Por eso, Patricia aprendió a sortear las críticas que le hacen las asociadas (es creída, gana mucho, 
le tienen envidia, etc.), moviéndose entre el conocimiento que la distancian de ellas, la vivencia compartida de las necesidades y la mala suerte (por ejemplo, la muerte constante de animales en su finca). Al resaltar sus dificultades se puede acercar a las asociadas, haciéndolas sentir iguales, pero cuando usa los conocimientos técnicos vuelve a distanciarse -se parece más a los de afuera- para sustentar sus virtudes como líder. También ha aprendido a evadir las críticas al hacer evidente el esfuerzo que suponen los trabajos directivos, como "hablar con personas creídas", "pelear", "estudiar", "trasnocharse", etc.

Cuando las críticas hacen referencia a que se está enriqueciendo con la asociación, o recibiendo más beneficios que las asociadas, debe justificar el trabajo que hace y disimular el beneficio obtenido. Como explica Micarelli (2015), disimular surge como derivación del orgullo del trabajo que hace ser a la persona, que se opone a la pereza y que se relaciona con el principio de que el poder se muestra por los hechos y no por las palabras. Por ejemplo, si usted le pregunta a Patricia por un viaje que le dieron en un proyecto, ella le va a responder que todo el día estuvo encerrada en conferencias y charlas, que fue aburrido (difícil) pero que entendió muchas cosas para la asociación. En este sentido, Patricia reconoce que le toca aprender para obtener los proyectos, aprender va más allá de conocer los formatos de aplicación a convocatorias (que cambian continuamente), también consiste en manejar estrategias para que las diferentes entidades acepten los proyectos.

Esto se debe a que esas mismas ideas tecnocientíficas fomentan la creación de una tecnocracia alrededor de los proyectos, esto significa que es la racionalidad económica la que guía las decisiones políticas, impulsada por un andamiaje de expertos y saberes institucionalizados. En este sentido, se prioriza lo objetivo y mensurable para la toma de decisiones referentes a diversas poblaciones (Ochoa y Estévez, 2006). Para cumplir esto, tanto Patricia como Gilma han estudiado carreras profesionales y han realizado diferentes cursos; esto implica otra expansión del saber experto (Dubois, 1991), pues no solo se encuentran los técnicos llevados por los proyectos, sino también están ellas mismas y las personas que contratan para aprender.

Incluso, parte de las estrategias que ellas usan para presentar proyectos, consiste en contratar una persona que conozca el formato de aplicación y las expectativas de los evaluadores (generalmente algún asistente o practicante de la gobernación), para que les ayude a formular el proyecto y presentarlo. Así, para acceder a los proyectos de desarrollo que llegan a la vereda, las directivas de AMEG se acercan cada vez más a ser 
unas tecnócratas. Machiavelli y Proulx (2006), al indagar por el tecnócrata, lo entienden como un técnico que se mueve entre el saber experto y el poder de gobernar o tomar decisiones. En algunos casos se ha criticado la asociación que se hace de estas personas con la "razón instrumental" en donde toda emoción perturba su juicio.

En la vereda, la emocionalidad continúa siendo fundamental, pues usted no sigue a Patricia porque haya una norma o estatuto, sino porque sabe que es una mujer guapa $a^{4}$ que tiene compromiso y las habilidades, porque esa gente usted la conoce de chiquita, son parientes, amigos o compadres, además los Rodríguez siempre han sido así. Es la emocionalidad, la razón y el parentesco lo que permite hacer negocios entre ellos (asociados de papa, contratación de mano de obra, venta de leche o productos, etc.) o tomar decisiones para beneficios comunes. La racionalidad no está en contra de la emocionalidad, las decisiones se reconocen mediadas por intenciones personales o de la familia, no por ello son condenadas, sino que usted puede criticar, cuestionar a las personas y buscar una solución directamente con quien tenga el conflicto. Así, se comprende que la razón y el sentimiento son indisolubles, pues "las personas desprovistas de emoción, aun cuando su funcionamiento cognitivo esté intacto, pierden el sentido de las prioridades y actúan basándose en el corto plazo; no conocen la duda, siempre están seguros de sus cálculos" (Machiavelli y Proulx, 2006, p. 200).

\section{Mil ojos mirando}

La envidia se convierte en un sentimiento central a la hora de regular y de entender la vida en la vereda. Este es un sentimiento despertado por la desigualdad que se percibe frente a otras personas que tienen algo que deseamos (objetos, prestigio, poder, etc.). Por eso, las ausencias entran a jugar un papel importante, pues cuando se excluye se crea desigualdad y se hace más evidente el poder, las jerarquías y la acumulación; frente a esta última la envidia tiene la capacidad de conservar la potencialidad propia de la necesidad. Por ello, hablábamos de no dejarse "enlechar", de la importancia de no acumular, pues es quitar un poco de esa fuerza que motiva el trabajo, que es parte fundamental para la vida campesina. Por eso, la envidia no es un sentimiento o una actitud adoptada hacia el objeto (el poder, el prestigio, etc.) sino hacia la persona que lo posee, es una actitud negada por quien la siente y temida por quien la despierta.

Una mujer guapa es aquella que se esfuerza mucho y trabaja en roles normalmente atribuidos a hombres (hace jornal, lidera una asociación, trabaja en construcción, entre otras.) con el objetivo de suplir una necesidad apremiante o para contribuir al bienestar comunitario. 
Las formas en las que se expresa pueden ser variadas, generalmente se presentan como críticas constantes, chismes, daños físicos directos y brujería (Foster et al., 1972). La envidia es muy temida por las directivas de la asociación, pues su liderazgo y continuidad recae en la confianza que ellas generan en sus asociadas, así que dañar su buen nombre es igual a dañar la asociación.

La tecnología se vuelve una muestra de distinción y separación, no sólo porque se vincula a lo moderno/desarrollado, sino porque a raíz de la implementación de máquinas en la asociación y en algunas fincas, se dejó de pedir mano de obra, esto implica que menos gente se beneficia de la asociación. Además, el trabajo va dejando de ser un proceso social a través del cual se crean lazos de amistad, aprendizajes e innovaciones; para autores como Van der Ploeg (2010) este aspecto del trabajo es fundamental para la continuidad de la producción agrícola campesina. Como a la asociación llegan tantas tecnologías de la mano de los proyectos, ellas se vuelven foco de envidias, lo que se ha reflejado en las constantes revisiones del INVIMA, que se convirtió en un arma de los envidiosos. Patricia y Gilma Rodríguez me explicaban que "no es que INVIMA vaya pasando y decida entrar a un lugar, deben venir con una carta, alguien los llama" (P. Rodríguez y G. Rodríguez, comunicación personal, 15 de febrero del 2018).

Estas historias sobre las revisiones de INVIMA se repiten constantemente, siempre vinculadas a algún grupo de personas envidiosas que llaman a la entidad (cooperativas vecinas, familiares inconformes y hombres de la vereda contra ellas). En una de estas ocasiones al terminar la historia, Patricia dice con preocupación que ya la tiene enferma tanta envidia que hay por ahí, a las pocas horas doña Leonor Rodríguez comienza a sentir unas punzadas en el estómago y afirma que es por tanta preocupación, de esta manera las relaciones sociales se materializan en el propio cuerpo envidiado o preocupado (Taussig, 2002). En cuanto a los proyectos, Patricia comentaba que:

El caso es que con tan mala energía fluyendo no se puede hacer nada que funcione. Por ejemplo, ese proyecto tan bueno y no sale bien, porque cualquier cosa que dan, ya son mil ojos viendo a ver qué es y por qué. (P. Rodríguez, comunicación personal, 11 de septiembre del 2018).

En estos distintos escenarios de envidia se puede ver que este sentimiento funciona como "principio organizativo para delinear el infortunio, como 'teoría' socio-psicológica del mal que fluye inevitablemente de la (percibida) desigualdad y como significación dominante 
de la perturbación en el nexo social" (Taussig, 2002, p. 474). Además, los espacios en los que se narran las situaciones desfavorables por envidia, permiten entender la propia experiencia de manera colectiva y el papel que se ocupa dentro de ella (Córdoba, 2011), es decir, entenderse dentro de ese entramado de relaciones de reciprocidad. Así, las directivas de AMEG pueden entender por qué es tan difícil mantener la asociación o pueden interpretar la renuncia de un familiar a la asociación como algo positivo a largo plazo, pues esa persona pudo ser quien llamó al INVIMA para cerrar la asociación en el 2015 y de ser así, es mejor tener lejos esa envidia. Por último, esta explicación permite entender por qué los proyectos no funcionan, cuando la tecnociencia y sus expertos prometen que van a funcionar sin importar el lugar donde se apliquen.

Así, las personas no se creen la ignorancia impuesta por otros y no consideran que sean sus propias acciones las que ocasionan las fallas de los proyectos. Pero tampoco culpan a los proyectos por sus fracasos, no son los beneficios los que están mal o las técnicas que enseñan, porque están hechas por expertos. Es la envidia de la cooperativa de al lado o del vecino o de la propia familia la que ocasiona que "las cosas se atascan y les es imposible ser lo que pretendían ser" (Holguín, 2019, p. 285). Por eso, un proyecto que pretendía hacer más productiva y estable la asociación no funciona, al punto de tener "las cosas que dan" (insumos) sin usar en distintos lugares de las casas o en la asociación.

Tanto las asociadas como las directivas han aprendido a lidiar con las deficiencias de los proyectos y a sacar los beneficios de ellos, esto se une al principio organizativo de la envidia para que ellas continúen aceptando y usando "de buena gana", pero con precauciones, los proyectos de desarrollo. Las precauciones que usted debe tener son: procurar ser amable, dar de lo que se tiene, sobre todo de eso que se tiene de más (como el toro o alguna máquina) y debe hacer favores. Por eso, usted debe estar dispuesto a romper ciertas reglas de la norma o los proyectos para cumplir alguna petición de una amistad o un familiar. Dar también significa incluir al mayor número de personas en los beneficios de los proyectos. Por ejemplo, Patricia acepta dos proyectos, uno para las asociadas oficiales y otro para los proveedores, de esta manera las que no puedan ingresar a uno de los proyectos se vinculan al otro.

Es decir que, aunque a la larga los proyectos debilitan la asociación y pueden fomentar la envidia externa, en el corto plazo y dentro de la asociación son una manera de "mantener a las asociadas contentas", logrando así estabilidad y continuidad. Así mismo, se contratan personas de la vereda para realizar trabajos del proyecto, como los conductores de 
tractor y los inseminadores. Por último, usted puede vender o regalar los beneficios del proyecto que no vaya a usar, asi se gana el afecto de algún vecino o familiar. De esta manera, se reduce al mínimo las exclusiones, mientras se redistribuye al máximo las ganancias, lo que previene las envidias que puede generar el ser parte de un proyecto de desarrollo.

\section{Conclusiones}

Tanto los Conpes del sector lácteo, como este tipo de proyectos derivados, han llevado una tecnociencia a la vereda que vuelve ausentes a las personas, pues ignora, juzga y castiga sus críticas, sus movimientos, sus prácticas y conocimientos, esto ha hecho que los proyectos sean poco efectivos y las producciones cada vez más difíciles de mantener. Pues al final, la mezcla de supuestos como la competitividad, la productividad y la higiene, responden a intereses de países extranjeros y están mediados por monoculturas violentas que atacan los comercios locales. De esta manera, son las campesinas las que cargan con todo el peso de transitar de una forma productiva inestable a una más segura y de volver funcionales los beneficios de los proyectos a su realidad, incluso transgrediendo y moviéndose entre las directrices de los mismos proyectos y de la normatividad láctea.

Por otro lado, la tecnociencia, al profundizar y crear ausencias, ha hecho más evidentes las jerarquías y desigualdades presentes en la vereda, lo que ha tenido como respuesta una continua sensación de envidias entre los vecinos. Esto, ya que la envidia tiene la función de evitar la acumulación mediante la crítica, el miedo y la vergüenza, pero también mediante el fomento de prácticas de reciprocidad que redistribuyen los beneficios de cualquier producción. Lo que a su vez quiere decir, dar continuidad a las formas de producción sinérgicas, como el préstamo del toro, que implican un afianzamiento de las redes vecinales y familiares. Al mismo tiempo, la envidia se convierte en la justificación que han encontrado las directivas y las asociadas para explicar el fracaso de los proyectos y de las tecnologías implementadas en la asociación.

Frente a esto, las asociadas y directivas han aprendido las precauciones necesarias para recibir los beneficios del desarrollo. Así, aunque "la expansión tecnocientífica es irreversible, no tiene que ser catastrófica para los grupos populares y el ambiente (...) [puede ser] la posibilidad de inventar nuevas formas de ser libre" (Escobar, 1998, p. 13). En AMEG se ha buscado la libertad y autonomía de las mujeres con su propia marca de derivados lácteos. A usted le tocó bregar para tener la asociación. Usar todo eso que conoce, los saberes viejos y los nuevos, esos que uno aprende 
de chiquita y también los que le enseñan en los cursos. Pero sabiendo que usted solo practica o usa lo que le queda lugar de hacer, porque con tanto oficio que toca todos los días no queda lugar, además algunas cosas salen más caras, ocupan más tiempo o le pueden dañar la relación con la familia. Por eso, usted decide que toma de los proyectos para sus propias necesidades, porque como decía doña Sofía la mamá de Patricia Rodríguez, "aunque nos digan ignorantes, nosotras sabemos" (S. Rodríguez, Comunicación personal, 18 de junio del 2018).

\section{Referencias bibliográficas}

Alcaldía Municipal de Guatavita (2014). Territorios. Nuestro municipio. Recuperado de http:// www.guatavita-cundinamarca.gov.co/territorios.shtml?apc=bbxx-1\&amp;x=1975338

Callon, M. (1995). Algunos elementos para una sociología de la traducción. La domesticación de las vieiras y los pescadores de la bahía de St. Brieuc. En J.M. Iranzo, J.R. Blanco, T.G. Fe, C. Torres y A. Cotillo (eds.), Sociología de la ciencia y la tecnología (pp. 259-282). Madrid: Consejo superior de investigaciones científicas.

Chatterjee, P., Chaves, M. y Hoyos, J. (2011). La política de los gobernados. Revista colombiana de antropología, 47(2), 199-231.

CONPES 3675. (19 de julio de 2010). Política nacional para mejorar la competitividad del sector lácteo colombiano.

CONPES 3676. (19 de julio de 2010). Consolidación de la política sanitaria de inocuidad para las cadenas láctea y cárnica.

Córdoba, A.L.R. (2011). Hacer de comer y brujería en una población rural en Boyacá: la enfermedad postiza. Maguaré, 25(2), 121-143.

De Sousa Santos, B. (2006). La sociología de las ausencias y la sociología de las emergencias: para una ecología de saberes. En Clacso (ed.), Renovar la teoría crítica y reinventar la emancipación social (pp. 13-41). Buenos Aires: Clacso.

Dubois, M. (1991). The Governance of the Third World. A Foucauldian Perspective of Power Relations in Development. Alternatives, 16(1), 1-30.

Echeverría, J. (2001). Tecnociencia y sistema de valores. En J. López y J. Sánchez (eds.) Ciencia, Tecnología, Sociedad y Cultura (pp. 221-230). Madrid: Biblioteca Nueva-OEI.

Escobar, A. (1998). La invención del Tercer Mundo: Construcción y deconstrucción del desarrollo. Bogotá: Norma.

Fajardo, D. (2018). Agricultura, campesinos y alimentos (1980-2010) (tesis de doctorado). Universidad Externado de Colombia, Bogotá, Colombia.

Foster, G.M., Apthorpe, R.J., Bernard, H.R., Bock, B., Brogger, J., Brown, J.K., ... y Freeman, S.T. (1972). The anatomy of envy: A study in symbolic behavior [and comments and reply]. Current anthropology, 13(2), 165-202.

Gallego, M. (2018) Conociendo cocinando: un análisis socio-ecológico de los conocimientos de la cocina y su articulación al turismo en Isla Fuerte (Bolivar) (tesis de pregrado). Pontificia Universidad Javeriana, Bogotá, Colombia. 
Giddens, A. (1997). Vivir en una Sociedad Postradicional Capítulo II. En U. Beck, A. Giddens y S. Lash (eds.), Modernización Reflexiva. Política, tradición y estética en el orden social moderno (pp. 75-137). Madrid: Alianza Editorial.

Gudeman, S. y Rivera, A. (1990). Conversations in Colombia: the domestic economy in life and text. London: Cambridge University Press.

Haraway, D. (2004). Testigo _ Modesto@ Segundo _ Milenio: HombreHembra@ Conoce Oncoratón (R). Feminismo y tecnociencia. Catalunya: Editorial Universitat Oberta de Catalunya.

Hobart, M. (2002). Introduction: the growth of ignorance? En M. Hobart (ed.), An anthropological critique of development: The growth of ignorance (pp. 1-30). Londres y Nueva York: Routledge.

Holguín, L. (2019). De lo floriado a lo marchito. El sistema del enrollamiento y la voluntad del barro en Aguabuena, Colombia. En L.A. Suárez-Guava (ed.), Cosas vivas. Antropología de objetos sustancias y potencias (pp. 267-288). Bogotá: Editorial Pontificia Universidad Javeriana.

Instituto Colombiano Agropecuario (ICA). (2007). Las buenas prácticas ganaderas en la producción de leche, en el marco del decreto 616. Bogotá: Imprenta Nacional de Colombia.

Kalmanovitz, S. y López, E. (2003). La agricultura en Colombia entre 1950 y 2000. Revista del Banco de la República, 76(912), 11-68.

Latour, B. (2001). La esperanza de pandora. Ensayos sobre la realidad de los estudios de la ciencia. Barcelona: Gedisa.

Machiavelli, F. y Proulx, D. (2006). Tecnocracia y decisión política. En H. Ochoa y A.M. Estévez (eds.), El poder de los expertos: para comprender la tecnocracia (pp. 191-216). Maracaibo, Universidad del Zulia.

Mauss, M. (1971). Ensayo sobre los dones: Razón y forma del cambio en las sociedades primitivas. En M. Mauss (ed.), Sociología y antropología (pp. 155-240). Madrid: Tecnos.

Max-Neef, M. y Elizalde, A. (1993). Desarrollo a escala humana: una opción para el futuro. Santiago de Chile: CEPAUR.

Micarelli, G. (2014). Indigenous Networks at the Margins of Development. Bogotá: Editorial Pontificia Universidad Javeriana.

Micarelli, G. (2015). Divine Banknote: The Translation of Project Money into Public Wealth. En F. Santos-Granero (ed.), Images of Public Wealth: Property, Identity, and Wellbeing in Native Amazonia (pp. 161-187). Tucson: University of Arizona Press.

Molano, A. (1998). Mi historia de vida con las historias de vida. En T. Lulle y L. Zamudio (eds.), Los usos de la historia de vida en las ciencias sociales (pp. 102-111). Lima: Antrophos.

Mora, J. (2008). Persistencia, conocimiento local y estrategias de vida en sociedades campesinas. Revista de estudios sociales, (29), 122-133.

Ochoa, H. y Estévez, A. (2006). El poder de los expertos: para comprender la tecnocracia. Maracaibo: Universidad del Zulia.

Pérez, E. y Farah, M. (2002). Los modelos de desarrollo y las funciones del medio rural en Colombia. Cuadernos de desarrollo rural, (49), 9-27. 
Salgado, C. (2002). Los campesinos imaginados (Vol. 6). Bogotá: Instituto Latinoamericano de Servicios Legales Alternativos, ILSA.

Scott, J. (2000). Los dominados y el arte de la resistencia. Discursos ocultos. Ciudad de México: Ediciones Era.

Scott, J.C. (1998). Seeing like a state: How certain schemes to improve the human condition have failed. Connecticut: Yale University Press.

Shiva, V. (1996). Abrazar la vida. Mujer, ecología y desarrollo. Montevideo: Instituto del Tercer Mundo.

Suárez, M. (2011). Colombia, una pieza más en el "nuevo mundo lácteo". Bogotá: Red Colombiana de Acción frente al Libre Comercio.

Taussig, M. (2002). Chamanismo, colonialismo y el hombre salvaje. Un estudio sobre el terror y la curación. Bogotá: Grupo Editorial Norma.

Van der Ploeg, J.D. (2000). Sistemas de conocimiento, metáfora y campo de interacción: el caso del cultivo de la patata en el altiplano peruano. En A. Viola (ed.), Antropología del Desarrollo: teoría y estudios etnográficos en América (pp. 359-383). Argentina: Paidós.

Van der Ploeg, J.D. (2010). Nuevos campesinos. campesinos e imperios alimentarios. Barcelona: Icaria Editorial.

Vargas-Monroy, L. (2010). De testigos modestos y puntos cero de observación: las incómodas intersecciones entre ciencia y colonialidad. Tabula rasa, (12), 73-94.

Villarraga, S. (2013). Acción colectiva en torno al manejo del recurso comunitario agua en el ecosistema altoandino de la vereda monquentiva, Guatavita- Cundinamarca (tesis de pregrado). Pontificia Universidad Javeriana, Bogotá, Colombia.

Wolf, E.R. y Cirlot, J.E. (1971). Los campesinos (vol. 126). Barcelona: Labor. 